\title{
In Doubt and Disorderly: Ambivalence Promotes Compensatory Perceptions of Order
}

\author{
Frenk van Harreveld and Bastiaan T. Rutjens \\ University of Amsterdam
}

\author{
Iris K. Schneider \\ VU University of Amsterdam
}

\author{
Hannah U. Nohlen and Konstantinos Keskinis \\ University of Amsterdam
}

\begin{abstract}
Ambivalence is a presumably unpleasant experience, and coming to terms with it is an intricate part of human existence. It is argued that ambivalent attitude holders cope with their ambivalence through compensatory perceptions of order. We first show that ambivalence leads to an increase in (visual) perceptions of order (Study 1). In Study 2 we conceptually replicate this finding by showing that ambivalence also increases belief in conspiracy theories, a cognitive form of order perception. Furthermore, this effect is mediated by the negative emotions that are elicited by ambivalence. In Study 3 we show that increased need for order is driving these effects: Affirmations of order cancel out the effect of ambivalence on perceptions of order. Theoretical as well as societal implications are discussed.
\end{abstract}

Keywords: ambivalence, attitudes, perceptions of order, compensatory coping, uncertainty

\begin{abstract}
As a result of the inborn conflict arising from ambivalence, of the eternal struggle between the trends of love and death - there is inextricably bound up with it an increase of the sense of guilt, which will perhaps reach heights that the individual finds hard to tolerate.
\end{abstract}

$$
\text { --Freud (1930/1964, p. 133). }
$$

Many scholars in the social sciences have argued that ambivalence is a primordial and unpleasant experience. Freud (1930/ 1964) saw the unpleasant nature of ambivalence as an intrinsic part of human existence, because, in his view, all intimate relationships contain a certain degree of ambivalence. Freud's notion that ambivalence is an intrinsic part of human existence is supported by research that has, for example, shown ambivalence in parent-child relationships (Luescher \& Pillemer, 1998); toward abortion (Alvarez \& Brehm, 1995), men (Glick \& Fiske, 1999), eating meat (Povey, Wellens, \& Conner, 2001), presidential candidates (Lavine, 2001), pregnancy (Brückner, Martin, \& Bearman, 2004), marriage (Signorielli, 1991), dieting (Armitage \& Arden, 2007), methadone treatment (Rosenblum, Magura, \& Joseph, 1992), and different ethnic groups (Katz \& Hass, 1988); among scientists

This article was published Online First March 3, 2014.

Frenk van Harreveld and Bastiaan T. Rutjens, Department of Social Psychology, University of Amsterdam, Amsterdam, the Netherlands; Iris K. Schneider, Department of Clinical Psychology, VU University of Amsterdam, Amsterdam, the Netherlands; Hannah U. Nohlen and Konstantinos Keskinis, Department of Social Psychology, University of Amsterdam, Amsterdam, the Netherlands.

We thank Jennifer Whitson for providing us with the modified snowy pictures task.

Correspondence concerning this article should be addressed to Frenk van Harreveld, University of Amsterdam, Department of Social Psychology, Weesperplein 4, 1018 XA Amsterdam, the Netherlands. E-mail: f.vanharreveld@uva.nl
(Mitroff, 1974); and between lovers sorting out their relationship (Wiseman, 1976).

Social psychological research supports the idea that ambivalence is undesirable, with researchers arguing that ambivalence can be unpleasant because it constitutes a violation of fundamental consistency motives (e.g., Jonas, Diehl, \& Brömer, 1997; Maio, Bell, \& Esses, 1996; McGregor, Newby-Clark, \& Zanna, 1999; Newby-Clark, McGregor, \& Zanna, 2002; Nordgren, van Harreveld, \& van der Pligt, 2006). This undesirable nature has been shown by studies relating ambivalence to physiological arousal (van Harreveld, Rutjens, Rotteveel, Nordgren, \& van der Pligt, 2009), negative mood (Hass, Katz, Rizzo, Bailey, \& Moore, 1992), narcissism (Slater \& Slater, 1965), negative behavior toward stigmatized persons (Katz, 1981), membership in countercultural groups (Yinger, 1982), and even burnout, schizophrenia, and victimization (cf. Coser, 1976; Wexler, 1983).

Given the ubiquitous as well as unpleasant nature of ambivalence, it becomes important to understand how people cope with ambivalence. As such, the current research aims to investigate ways through which people aim to compensate for the unpleasant experience of ambivalence. We suggest in particular that ambivalence inherently is an experience of disorder that people cope with by compensatory perceptions of order.

\section{Defining and Distinguishing Ambivalence}

Ambivalence shares features with other inconsistency-related psychological threats, such as cognitive dissonance or general uncertainty; however, it can be conceptually distinguished from these constructs in several ways. First, on a structural level, ambivalence can be understood as a state in which an individual "is inclined to give it [an attitude object] equivalently strong positive or negative evaluations" (Thompson, Zanna, \& Griffin, 1995, p. 367). Ambivalence is thus an intra-attitudinal discrepancy contrary 
to cognitive dissonance, which is generally investigated in the context of discrepancies between attitudes or between attitudes and behavior.

The unique characteristics of ambivalence also clearly distinguish it from uncertainty. First, ambivalence is not uniquely tied to uncertainty. Thinking about both sides of an issue can even enhance attitude certainty, despite activating conflicting information (Rucker \& Petty, 2004; Rucker, Petty, \& Brinol, 2008). Clarkson, Tormala, and Rucker (2008) provided a nice illustration of this apparent contradiction with the example of someone who is highly certain about both the positive (e.g., tastes good) and negative (e.g., high in calories) aspects of chocolate and thus is very certain of his or her ambivalence toward this sugary treat. Second, in terms of attitude strength, ambivalence loads on the operative factor, whereas uncertainty loads on the meta-attitudinal factor of attitude strength (Bassili, 1996). Third and finally, Nohlen, van Harreveld, Rotteveel, Lelieveld, and Crone (2013) recently related ambivalence not only to activation of the anterior cingulate cortex (ACC; known to also be activated under uncertainty) but also to activation of the insula, temporal parietal junction, and posterior cingulate cortex/precuneus. This arguably social-affective network has not been related to uncertainty or to other psychological threats.

Although on a conceptual level ambivalence can be distinguished from other psychological threats, ambivalence is related to aversive arousal (e.g., van Harreveld, Rutjens, et al., 2009) and ACC activation (Nohlen et al., 2013). As such, it holds some experiential resemblance with other inconsistency-related psychological threats (Proulx, Inzlicht, \& Harmon-Jones, 2012). In the current research we examine the aversive experience of ambivalence and aim to further our understanding of how people cope with ambivalence.

\section{Dealing With Ambivalence}

Following from the apparent unpleasant and ubiquitous nature of ambivalence, an impressive body of research has addressed the question of how ambivalent attitude holders cope with their psychological discomfort. Research on how people cope with the experience of ambivalence has mainly focused on the motivation to reduce ambivalence itself (see van Harreveld, van der Pligt, and de Liver, 2009, for an overview). In general there are two ways in which people can cope with their ambivalence. First, they can do so in a direct way, by attacking the ambivalent attitude. For instance, a considerable amount of research suggests that ambivalent attitude holders invest cognitive resources in order to come to a more unequivocal attitude. Studies have shown, for example, that ambivalence is related to a more effortful process of integrating attributes when forming an attitude (van Harreveld \& van der Pligt, 2004; van Harreveld, van der Pligt, de Vries, Wenneker, \& Verhue, 2004). Other studies indicate that ambivalence is associated with more attitude-related thoughts (Jonas et al., 1997), increased cognitive activity (Monteith, Devine, \& Zuwerink, 1993), greater ventrolateral prefrontal cortex activity (Cunningham, Johnson, Gatenby, Gore, \& Banaji, 2003), and a larger difference in the effectiveness of strong and weak persuasive messages (Maio et al., 1996). Increased receptiveness of ambivalent attitude holders to strong persuasive messages indeed helped to reduce subsequent feelings of ambivalence. Biased systematic processing and the use of specific heuristics can also provide effective ways to combat ambivalence and change the attitude altogether. Clark, Wegener, and Fabrigar (2008), for example, found that ambivalent attitude holders focus on proattitudinal information and avoid counterattitudinal information. In other words, ambivalent attitude holders process information in accordance with the slight evaluative inclination they may have (see also Nordgren et al., 2006). Thus, research on the consequences of ambivalence has extensively addressed ways in which ambivalent attitude holders aim to swing the balance within their attitude.

The process in which attitude holders try to change their attitude in order to reduce ambivalence can be understood as problemfocused coping. However, there are other ways in which to cope with ambivalence. The model of ambivalence induced discomfort (van Harreveld, van der Pligt, \& de Liver, 2009) also distinguishes emotion-focused coping strategies as a way of dealing with ambivalence. Emotion-focused strategies (procrastinating the decision on the one hand and downplaying the importance of the decision on the other) are more indirect; they are aimed at reducing the unpleasant nature of ambivalence but do not affect the ambivalent attitude itself. Both problem-focused and emotion-focused strategies occur in relative proximity of the attitude, as they relate to an imminent ambivalent decision.

The idea that people may combat the unpleasant nature of ambivalence but not the attitude per se is in accord with the idea that psychological threats, such as ambivalence, can be combated with proximate strategies. Ambivalence (van Harreveld, van der Pligt, \& de Liver, 2009), cognitive dissonance (Brehm, 2007), threats to meaning (e.g., Proulx \& Heine, 2008), and violations of schemata (Muller, Carpendale, \& Smith, 2009) have indeed been related to palliative responses aimed at accommodation or assimilation (Proulx \& Inzlicht, 2012). Accommodation on the one hand is defined as revising expected relationships so that they are consistent with experiences. In the context of ambivalence this refers to the aforementioned changing of the attitude and reducing ambivalence altogether (cf. the aforementioned problem-focused coping strategies). Assimilation on the other hand is defined as reinterpreting experiences in such a way that they are consistent with expected relationships. In the context of ambivalence this refers to the aforementioned process of downplaying the importance of an ambivalent decision (cf. emotion-focused coping).

\section{Compensatory Coping}

Apart from these processes that occur in relative proximity to the threat, coping with psychological threat also occurs in ways that are more distal to the threat itself; for example, through a process of affirmation. Affirmation is defined as

\footnotetext{
heightened commitment to alternative expected relationships following the violation of expected relationships. The affirmed expected relationships may share content with the violated relationships (e.g., affirming a controlling God after personal control has been violated) or share no content with the violated expected relationships (e.g., punishing a criminal more harshly following a visual anomaly). (Proulx et al., 2012, p. 285)
}

Our present focus on (ambivalence-induced) compensatory perceptions of order fits very well within this category of affirmation, particularly with the latter form describing the affirmation of 
expected relationships that share no content with the violated expected relationships. Examples of such affirmation processes are found in the context of various other kinds of psychological threat, such as personal uncertainty (van den Bos, 2001), absence of personal control (Kay, Whitson, Gaucher, \& Galinsky, 2009), mortality salience (Greenberg, Solomon, \& Pyszczynski, 1997), and goal frustration (McGregor, Nash, Mann, \& Phills, 2010). As such it seems that this type of coping can be beneficial in dealing with psychological threats, including ambivalence. However, so far, no research has investigated the relation between ambivalence and compensatory coping efforts.

This is surprising, given the fact that other (cognitive) inconsistencies that have been related to ambivalence, such as cognitive dissonance (McGregor et al., 1999), are known to facilitate compensatory coping strategies. Steele and Liu (1983), for example, argued that when people experience cognitive dissonance, this constitutes a threat to the self. They showed that there are many other ways to compensate for such a threat than by changing one's attitude and regaining consonance. Their studies for instance indicated that affirming one's personal values can also be an effective means to reduce dissonance. Similarly, research has shown that when their self-integrity is threatened, people resort to more extreme convictions about social issues in an attempt to mask their personal uncertainty (McGregor, Zanna, Holmes, \& Spencer, 2001). It thus has been shown that people can cope with a specific threat to their self-integrity through compensatory coping, much along the lines of Freud's (1915/1964) concept of displacement. Although self-discrepancy theory (Higgins, 1987) has not explicitly been related to ambivalence, ambivalent attitude holders are confronted with a discrepancy between their actual (ambivalent) attitude and their ideal (univalent) attitude. As such one could argue that ambivalence also constitutes a threat to one's selfintegrity. Thus, ambivalence may foster compensatory coping strategies, similar to dissonance and other threats to self-integrity.

However, given the unique characteristics that distinguish ambivalence from uncertainty (e.g., the inherent certainty about opposing thoughts and/or feelings that characterized ambivalence), it remains to be seen whether ambivalence can also lead to such compensatory coping strategies. In the current paper we therefore examine whether ambivalence also makes people look beyond the context of the attitude itself and employ more distal, compensatory, coping strategies. We focus more specifically on compensatory perceptions of order.

\section{Ambivalence and Order}

Even though compensatory coping comes in many forms, the current work specifically examines compensatory perceptions of order because ambivalence and order are closely related. Ambivalence is defined by the coexistence of evaluatively incongruent thoughts and/or feelings, violating the consistency humans prefer in their world (e.g., Heider, 1946). As such, the experience of ambivalence is inherently one of perceived internal (evaluative) disorder. One potentially effective affirmation strategy when confronted with experiences of disorder lies thus in compensatory perceptions of order. This is indicated by research that has shown that compensatory perceptions of order are enhanced by perceptions of randomness and low control (Kay et al., 2009). These compensatory perceptions can manifest themselves in a variety of ways (e.g., Whitson \& Galinsky, 2008). For example, control threats have shown to foster visual illusory pattern perception but also to enhance belief in conspiracies. Conspiracy beliefs represent complex events in a simplified and often monocausal way, and as such they provide in a need for order and predictability. We believe that ambivalence encompasses an experience of disorder very much similar to threats such as lack of control. In our view ambivalence should be understood as a state of internal disorder that is likely to generate a general need to restore order perceptions. Our aim in the present work is to investigate this hypothesis.

\section{Overview of the Present Studies}

In the present paper we examine whether ambivalent attitude holders cope via a process of affirmation (Proulx \& Inzlicht, 2012). In particular, we expect ambivalence to cause people to try and compensate for the inconsistency within their attitude, leading to enhanced perceptions of order. We present three studies in which we manipulate ambivalence and test the assumption that ambivalence fosters perceptions of order. Across the studies we focus on different order perceptions. In our first study we relate ambivalence to a perceptual measure of order. In the second study we assess ambivalent and nonambivalent participants' beliefs in conspiracy theories, as these have also been related to the motivation to perceive order (Whitson \& Galinksy, 2008). In this study we also examine whether the expected effects of ambivalence on belief in conspiracy theories are driven by the negative emotions that are elicited by ambivalence. In the third and final study we investigate whether the effect of ambivalence on visual perceptions of order disappears after a preceding affirmation of order. The current research thus aims to provide insight into hitherto uninvestigated means to cope with the experience of ambivalence; namely, compensatory order perceptions.

\section{Study 1}

In the first study we compared ambivalent attitude holders to those who are univalent and those in a control condition. For each of these groups we assessed illusory pattern perception with a modified version of the original snowy pictures task (Ekstrom, French, Harman, \& Dermen, 1976). This task has been used in earlier research to show that lack of control triggers illusory pattern perception, which functions as a compensatory control mechanism by imposing structure on the world and the environment (Whitson \& Galinsky, 2008). In the present study we examine whether ambivalence triggers similar perceptions.

\section{Method}

Participants and design. Sixty-four University of Amsterdam students (53 female, 6 male, 5 missing values, $M_{\text {age }}=20.95$ years, $S D_{\text {age }}=2.59$ ) participated in the study in return for course credit or a 7-euro reward. They were randomly assigned to the ambivalent $(N=22)$, univalent $(N=21)$, or control $(N=20)$ condition.

Materials and procedure. As a manipulation of attitudinal ambivalence in the ambivalence and univalence conditions we presented participants with a fake newspaper article (cf. van Harreveld, Rutjens, et al., 2009) about a political debate on abortion 
laws. ${ }^{1}$ We produced two versions of a newspaper article, supposedly from NRC Handelsblad, a quality newspaper in the Netherlands. Participants in the ambivalent condition were presented with an article that addressed the pros and cons of shortening the period during which abortion is allowed. In the univalent condition they read an article that addressed only the advantages of such new legislation. Participants in the control condition read no newspaper article and went straight to the dependent measure.

As a manipulation check we administered the measure of subjective ambivalence by Priester and Petty (1996). The measure consists of three 9-point items that read "Towards this topic I . .." and that were respectively anchored with feel no conflict at all, feel no indecision at all, and have completely one-sided reactions (1) and feel maximum conflict, feel maximum indecision, and have completely mixed reactions (9). We have opted for this measure because, although other measures focus on the affective (Jamieson, 1993) or cognitive (Kaplan, 1972) nature of ambivalence, the Priester and Petty measure is a holistic measure of ambivalence that is based on the tripartite model of attitudes (e.g., Ostrom, 1969). It encompasses the affective, cognitive, and behavioral component of ambivalence and is in our view the most comprehensive and most widely used measure of ambivalence (see also Priester \& Petty, 2001). Ambivalence scores were calculated by averaging the responses to these three questions $(\alpha=.92)$. Participants in the control condition read no newspaper article and were immediately presented with the dependent measure.

The dependent measure employed in this study assessed participants' visual pattern perception with a modified version of the original snowy pictures task (Ekstrom et al., 1976) that was adapted in a way similar to that in Whitson and Galinsky (2008). In this adaptation 12 of the 24 pictures were taken from the original task and contained a grainy embedded image that was difficult to perceive. The other 12 pictures were manipulated in such a way that any traces of the embedded image were removed. The images and non-images were presented in a mixed order, and participants were asked to say if they saw an image and, if so, describe what the image was. Illusory pattern perception was calculated by adding the number of times participants saw an image where none existed (cf. Whitson \& Galinksy, 2008). Participants' demographics were recorded after presentation of this modified snowy pictures task, and participants were subsequently thanked and debriefed.

\section{Results and Discussion}

The results revealed significantly higher scores on the Priester and Petty (1996) measure in the ambivalent condition $(M=4.73$, $S D=1.59)$ than in the univalent (negative) condition $(M=3.67$, $S D=1.80), F(1,42)=4.29, p=.044, \eta_{\mathrm{p}}^{2}=.09$. The manipulation of ambivalence was thus successful.

Preliminary analyses of the modified snowy pictures task first of all showed that, in accordance with earlier research (Whitson \& Galinsky, 2008), participants see most of the 12 pictures that are actually there and that, as expected, the control $(M=10.95, S D=$ $1.36)$, univalent $(M=10.77, S D=1.02)$, and ambivalent $(M=$ $10.91, S D=1.54)$ conditions did not differ from each other $(F<$ 1). Participants detected between 0 and 10 figures in the 12 pictures that in fact did not contain figures $(M=3.37, S D=2.62)$. A one-way analysis of variance comparing the three experimental conditions in terms of their respective number of false positives on the modified snowy pictures task showed a significant effect, $F(2$, $61)=3.34, p=.042, \eta_{\mathrm{p}}^{2}=.10$. Least significant difference post hoc tests showed that participants in the ambivalent condition displayed more illusory pattern perception $(M=4.50, S D=2.84)$ than did those in the univalent condition $(M=2.82, S D=2.48)$ or the control condition $(M=2.75, S D=2.17 ; p=.031$ and $p=$ .028 , respectively). The univalent and control conditions did not differ significantly ( $p=.93)$.

We also correlated self-reported levels of ambivalence, as assessed with the Priester and Petty (1996) measure, with the number of false positives on the modified snowy pictures task. The results confirm that higher levels of ambivalence are related to an increase in illusory perceptions of order $(r=.32, p=.037)$. Our expectation that ambivalence results in illusory pattern perception was thus confirmed.

\section{Study 2}

As we have argued above, we believe that the increased perceptions of order for ambivalent attitude holders is caused by a desire to compensate for their internal evaluative disorder. More precisely, ambivalence is a state of internal inconsistency that can be experienced as unpleasant (e.g., van Harreveld, Rutjens, et al., 2009), and we believe it is this unpleasant nature that facilitates a search for order and structure. In the next study we therefore aim to show that the increased order perceptions by ambivalent attitude holders is driven by the unpleasant affective nature of ambivalence.

As we have stated in the introduction, ambivalence and uncertainty are conceptually distinct, but related, constructs. Recent research has consistently shown that ambivalence can lead to feelings of uncertainty and anxiety (van Harreveld, Rutjens, et al., 2009) and that these affective consequences of ambivalence ignite subsequent coping processes (e.g., Nordgren et al., 2006). In the next study we therefore measure a set of such emotions to assess the potential unpleasant nature of ambivalence (van Harreveld, van der Pligt, \& de Liver, 2009) to determine whether ambivalence must be unpleasant to foster a desire for perceptions of order. A potential mediating role of these emotions would substantiate our belief that it is ambivalence-induced discomfort that facilitates a search for order.

Moreover, we employ a different dependent measure than in Study 1. Drawing on the literature on coping with control threats, we assess belief in conspiracy theories as providers of order. It has been argued that conspiracy theories give causes and motives to events that are more rationally seen as accidents (Pipes, 1997). As such, conspiracy theories provide a sense of order, and in earlier

\footnotetext{
${ }^{1}$ In the Netherlands, abortion is currently allowed until 24 weeks of pregnancy. However, as a result of medical progress, fetuses can now survive premature births at 24 weeks of pregnancy. As a result, some political parties believe that abortion should not be allowed after the 22nd week of pregnancy. Others believe that such new legislation has unwanted consequences. They argue that important tests of the health of the fetus are performed at 20 weeks. These tests take 2 weeks, and, in the opinion of those who oppose the new legislation, the parents should be allowed some time to contemplate their decision. In their view, shortening the period of time during which abortion is allowed to 22 weeks would hasten parents in having to make such an important decision.
} 
research conspiracy beliefs have been related to threats to personal control (cf. Whitson \& Galinsky, 2008). In the next study we therefore examine whether conspiracy beliefs increase as a result of attitudinal ambivalence. Additionally, we assess whether such an increase is caused by ambivalence-induced negative emotions.

\section{Method}

Participants and design. Thirty-eight University of Amsterdam students (26 female, 10 male, 2 missing values, $M_{\text {age }}=24.05$ years, $S D_{\text {age }}=8.67$ ) participated in the study in return for course credit or a 7-euro reward. They were randomly assigned to either the ambivalent $(N=19)$ or the univalent $(N=19)$ condition.

Materials and procedure. In the current study we used a different manipulation than we did in Study 1. It has been argued that merely engaging in introspection about one's ambivalence can already render it unpleasant (van Harreveld, van der Pligt, \& de Liver, 2009). Along these lines, and in accordance with earlier research by Schneider et al. (2013), in the current study we manipulated attitudinal ambivalence with an introspective task. More specifically, we asked participants in the ambivalent condition, "First of all, we want to ask you to think of a topic. This can be anything, as long as it is something you are ambivalent about. In other words think of something you have mixed thoughts or feelings about." Participants in the univalent condition were told, "First of all, we want to ask you to think of a topic. This can be anything, as long as it is something you have a clear and unequivocal opinion about. In other words something you are either positive or negative about." Participants in both conditions were subsequently asked to write down what topic they felt ambivalent (or univalent) about. Participants in the ambivalent condition were then presented with four numbered lines on which they could write their positive thoughts and/or feelings regarding their chosen topic and four numbered lines on which they could write their negative thoughts and/or feelings regarding their chosen topic. Participants in the univalent condition were presented with 8 numbered lines on which they could write their thoughts regarding their chosen topic (without distinguishing them in terms of valence). The reason we had participants write about their self-chosen topics was twofold. First, writing about a topic would make their ambivalence (or univalence) more salient. Second, this allowed us to examine whether participants' reported thoughts are indeed more two-sided in the ambivalent condition and one-sided in the univalent condition. The manipulation check was the same as in the previous study $(\alpha=.91)$.

After conducting the manipulation check, we presented participants with a scale aimed at assessing negative emotions to tap into the unpleasant experience ambivalence can be. This scale consisted of five items, "At the moment I feel ..." (uncertain, anxious, irritated, doubtful, nervous), with response options ranging from disagree (1) to agree (9). The alpha of this scale was .80 .

Participants were subsequently presented with the same two scenarios that Whitson and Galinsky (2008) used to assess belief in conspiracy theories. In these scenarios, the protagonist was confronted with a positive or negative outcome. It was possible to interpret the outcome as the result of conspiratorial behavior of people around the protagonist, but the conspirational nature of the situation was ambiguous. The first scenario describes a negative outcome, and participants were asked to what extent this outcome might be due to the actions of other people in the scenario:

\begin{abstract}
Imagine that you are one of the top administrators in your organization. You are in charge of running a number of aspects of the organization, including tracking the hours of all employees and their email and Internet usage. You will soon be up for promotion. The day before your scheduled meeting with your superiors, you notice that the number of emails between your boss and the coworker sitting next to you jumps precipitously. When you meet with your boss, you are told you're not getting the promotion. To what extent do you think your coworker may be connected to you not getting the promotion?
\end{abstract}

In the second scenario, the protagonist experiences a positive event and is asked to what extent that might be due to the actions of other people in the scenario:

\begin{abstract}
Imagine that you buy stock in one of the three construction companies that service your area. One day, your spouse, who runs the local bed and breakfast, notes that the families of all three company owners have checked into the $\mathrm{B} \& \mathrm{~B}$ recently. Later, the prices all three companies offer for their services have risen drastically. Because of the higher prices, all three companies post very high profits, and you make a lot of money off of the stock you own. To what extent do you think the visits to the bed and breakfast may be connected to the earnings you made off your stocks?
\end{abstract}

Participants rated the extent to which other people's actions in the scenario were connected to the protagonists' outcomes on scales ranging from 1 (not at all) to 9 (a great deal). Both ratings were averaged to generate a conspiracy belief score After participants had completed the dependent measures, we assessed their demographics. They were subsequently thanked and debriefed.

\section{Results and Discussion}

The results revealed significantly higher scores on the Priester and Petty (1996) measure in the ambivalent condition $(M=5.95$, $S D=1.21)$ than in the univalent condition $(M=2.23, S D=1.57)$, $F(1,36)=66.88, p<.001, \eta_{\mathrm{p}}^{2}=.65$. We also examined the thoughts participants had in relation to their chosen ambivalent (univalent) topic. Participants reported between 1 and 8 thoughts $(M=5.92, S D=2.16)$. In the ambivalent condition, participants thought of topics such as development aid, organ donation, nuclear energy, budget cuts, smoking, and euthanasia. Participants in the univalent condition thought of topics such as pedophilia, premarital sex, and the suffering of animals in the meat industry. We tested whether participants in the ambivalent condition were less polarized in their thoughts about the attitude object. We did this by taking the number of reported positive $(\mathrm{P})$ and negative $(\mathrm{N})$ thoughts and entering them into the formula by Thompson et al. (1995): $(P+N) / 2-[P-N]$. The scores on this measure ranged from -4 to 4 , where higher scores represented more two-sided (ambivalent) thoughts. Scores on this measure correlated highly with the Priester and Petty measure $(r=.82, p<.001)$. The results showed that also on this measure participants were significantly more ambivalent $(M=3.05, S D=0.93)$ in the ambivalent condition than in the univalent condition $(M=-2.23, S D=1.39)$, 
$F(1,35)=191.44, p<.001, \eta_{\mathrm{p}}^{2}=.84 .^{2}$ Our manipulation of ambivalence was thus successful.

We subsequently compared both experimental conditions in terms of their conspiracy beliefs. The results indicated that participants in the ambivalent condition had stronger conspiracy beliefs $(M=6.18, S D=1.34)$ than did their counterparts in the univalent condition $(M=5.21, S D=1.22), F(1,36)=5.52, p=.024, \eta_{\mathrm{p}}^{2}=$ .13. Moreover, self-reported ambivalence, as assessed with the Priester and Petty (1996) measure, was significantly related to conspiracy beliefs $(r=.41, p=.01)$, as was the ambivalence measure based on the generated thoughts $(r=.39, p=.02)$. These results confirmed our expectation that attitudinal ambivalence increases adherence to conspiracy theories. ${ }^{3}$

Next we compared the experimental conditions in terms of their self-reported negative emotions. In accordance with our expectations, participants in the ambivalent condition reported more negative emotions $(M=3.94, S D=1.25)$ than did their counterparts in the univalent condition $(M=2.41, S D=1.56), F(1,36)=$ 11.02, $p=.002, \eta_{\mathrm{p}}^{2}=.23$. Moreover, level of self-reported ambivalence, as assessed with the Priester and Petty (1996) measure, was related to negative emotions ( $r=.75, p<.001)$, as was the ambivalence measure based on generated thoughts $(r=.37$, $p=.02)$. Ambivalence was thus experienced as unpleasant. The measure of self-reported negative emotions was also correlated with belief in conspiracy theories $(r=.43, p<.01)$.

We expected the effect of ambivalence on belief in conspiracy theories to be contingent upon the unpleasant nature of ambivalence. Therefore we examined whether the self-reported negative emotions mediated the effect of our ambivalence manipulation on conspiracy beliefs. This expectation was confirmed (see Figure 1). A bootstrapping analysis of 5,000 samples confirmed that the indirect effect of ambivalence on conspiracy beliefs (through negative emotions) was different from zero (a point estimate of 40 was yielded, $95 \%$ bootstrap CI .09 to .89).

The results of this second study indicate that ambivalenceinduced discomfort causes an increased belief in conspiracies and that specific emotional responses that are elicited by ambivalence mediate this effect. This study thus substantiates our notion that it is the unpleasant nature of ambivalence that fosters a desire to perceive compensatory order in the outside world.

\section{Study 3}

The two studies thus far presented in this paper have shown that the discomfort elicited by ambivalence facilitates various perceptions of order and that these perceptions are driven by the negative emotional responses elicited by ambivalence. In the third and final study we more directly examine the supposed motivational nature of these perceptions of order. If it is indeed the case that ambivalent attitude holders are motivated to perceive order, one would expect that an affirmation of order subsequent to the ambivalence manipulation diminishes the need to perceive order (for ambivalent attitude holders). This effect is somewhat reminiscent of how self-affirmation can diminish the need to reduce cognitive dissonance through attitude change (e.g., Steele \& Liu, 1983). In this final study we again assess whether ambivalence fosters visual perceptions of order via the modified snowy pictures task, but we also assess whether affirming participants' perceptions of order makes ambivalent attitude holders less inclined to engage in com-

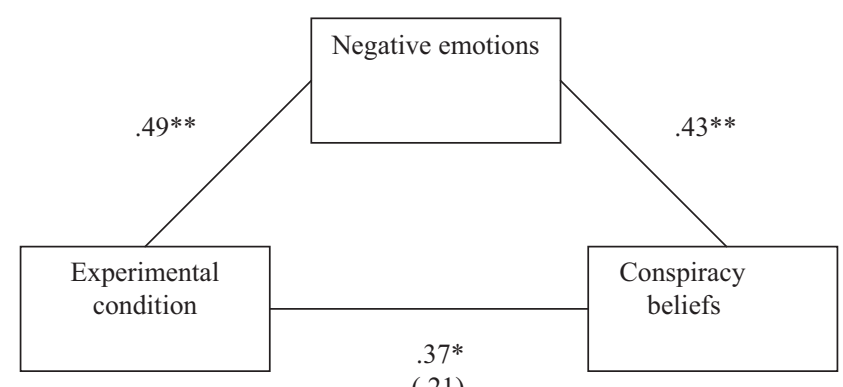

$(.21)$

Figure 1. Standardized regression coefficients for the relationship between the experimental manipulation of ambivalence and conspiracy beliefs as mediated by experienced negative emotions. The standardized regression coefficient between experimental condition and conspiracy beliefs controlling for negative emotions is in parentheses. ${ }^{*} p<.05$. ${ }^{* *} p<$ 01 .

pensatory perceptions of order. Such a finding would further indicate that ambivalence generates a need for compensatory order.

\section{Method}

Participants and design. Ninety University of Amsterdam students participated in the study in return for course credit or a 3.50-euro reward. Ten participants were excluded because they refused to execute the affirmation of order task (8) or expressed suspicion about that same manipulation (2). The final sample thus consisted of 80 participants (52 female, $M_{\text {age }}=22.11$ years, $S D_{\text {age }}=5.48$ ). A 2 (ambivalence vs. univalence) $\times 2$ (order vs. disorder) design was used, and participants were randomly distributed over the four conditions ( $N=20$ for each condition).

Materials and procedure. All participants were seated in an individual cubicle, where they were led through the experiment by a computer task. We first manipulated ambivalence (univalence) with the earlier introspective procedure. Again the manipulation was followed by the Priester and Petty (1996) measure as a manipulation check $(\alpha=.85)$. An error message subsequently appeared on the screen, and participants were told that the next questionnaire could not be found on the computer. The experimenter told the participants that they would therefore have to proceed with the experiment in a different cubicle. The experimenter led them to a different cubicle, which was very disorderly. Several things, such as books, pens, creased pieces of paper, and

\footnotetext{
${ }^{2}$ We also analyzed the valence of the generated thoughts and found that participants in the ambivalent condition generated more positive thoughts $(M=3.15)$ than did their counterparts in the univalent condition $(M=$ 1.84), $F(1,55)=4.38, p<.05$. However, the number of positive (or negative) thoughts was not significantly related to the dependent measure

${ }^{3}$ One could argue that some of the topics participants chose to write about in the ambivalent condition are related to mortality salience and threats to control, both topics that are known to lead to compensatory beliefs (e.g., Kay, Gaucher, McGregor, \& Nash, 2010; Rutjens, van der Pligt, \& van Harreveld, 2009). When we ran our main analysis without the 7 participants who wrote about topics that may relate to mortality and/or control (e.g., smoking, nuclear energy, euthanasia), the effect of ambivalence on conspiracy beliefs (despite the reduced power) was still significant at $p=.04$.
} 
magazines, were positioned on the table or the floor in a disorderly way but without blocking participants' movements (nothing was placed close to the keyboard or mouse). These objects were positioned in exactly the same way every time. In the order condition, participants were told that they could not work properly in this disorderly room and were asked to help the experimenter order things. In the disorder condition, they worked in this cubicle without being told to create order (and indeed without doing so) but completed an irrelevant task for 1 to 2 minutes (writing down words about the drinks they had consumed during the last 48 hours). All participants then continued with the same modified snowy pictures task as in Study 1. At the end of the session participants were presented with a manipulation check of (dis)order, "The place I am working in now is . . .," with a scale ranging from 1 (disorderly) to 9 (orderly). Participants' demographics were recorded after this task, and participants were subsequently thanked and debriefed.

\section{Results and Discussion}

To investigate if our manipulation of ambivalence was successful, we first compared the ambivalence and univalence condition in terms of their experienced ambivalence. Participants in the ambivalent condition scored higher on the Priester and Petty (1996) measure $(M=5.80, S D=1.02)$ than did their counterparts in the univalent condition $(M=3.37, S D=1.42), F(1,78)=76.89, p<$ $.001, \eta_{\mathrm{p}}^{2}=.50$.

Next we computed how many positive or negative thoughts participants expressed about the ambivalent or univalent topic. They wrote down between 1 and 8 positive $(\mathrm{P})$ or negative $(\mathrm{N})$ thoughts and feelings about these topics. Using the formula of Thompson et al. (1995): $(P+N) / 2-[P-N]$, we computed a score from -4 (more one-sided or univalent thoughts) to 4 (more twosided or ambivalent thoughts). As in the previous studies, participants in the ambivalent condition reported more ambivalent thoughts and feelings $(M=3.21, S D=0.83)$ than did those in the univalent condition $(M=-2.11, S D=1.41), F(1,78)=424.57$, $p<.001, \eta_{\mathrm{p}}^{2}=.85$. Our manipulation of ambivalence was thus successful.

To determine the effectiveness of our order manipulation, we examined whether or not tidying up the cubicle influenced the evaluation of the workplace. In the order condition, participants evaluated the workplace as more orderly $(M=5.93, S D=2.80)$ than they did in the disorder condition $(M=2.50, S D=2.20)$, $F(1,78)=37.13, p<.001, \eta_{\mathrm{p}}^{2}=.32$. Moreover, the ambivalence manipulation did not significantly influence evaluations of the environment ( $p=.11$ ) and did not interact with the environmental order manipulation $(F<1)$. Therefore, our manipulation of (dis)order was also successful.

To test the effects of the ambivalence and order manipulations on illusory pattern perceptions, we distinguished between real images and non-images. As in Study 1, participants recognized most of the existing images $(M=11.21, S D=1.01)$. There was only a marginal effect of the order manipulation, $F(1,78)=3.62$, $p=.061$. Cleaning the cubicle led participants to see slightly fewer images $(M=11.00, S D=1.11)$ than did not doing so $(M=$ $11.43, S D=0.87)$. Perhaps more important, there was no effect of the ambivalence manipulation on the existing images $\left(M_{\text {ambivalent }}=\right.$
11.28, $\left.S D=0.88, M_{\text {univalent }}=11.15, S D=1.14, F<1\right)$, and there was no interaction between the two manipulations.

As in Study 1 we focused on the number of false positives as our measure of order perceptions. On this measure we found a significant interaction between the manipulations of ambivalence and order, $F(3,76)=11.08, p=.001, \eta_{\mathrm{p}}^{2}=.13$. An analysis of simple main effects revealed the expected effect of ambivalence within the disorder condition, $F(1,78)=16.83, p<.001$. No such effect appeared after an affirmation of order $(p=.55)$. Least significant difference post hoc tests confirmed that ambivalence/disorder condition $(M=9.15, S D=3.53)$ differed significantly from the ambivalence/order $(M=5.45, S D=3.83)$, univalence/disorder $(M=4.40, S D=2.80)$, and univalence/order $(M=6.15, S D=$ 4.32 ) conditions ( $p=.002, p<.001$, and $p=.01$ respectively), but the other three did not differ from each other $(p s>.13){ }^{4}$

As in Study 1 we found an effect of the ambivalence manipulation on illusory perceptions of order, $F(1,78)=5.39, p=.023$, $\eta_{\mathrm{p}}^{2}=.07$, as well as a significant correlation between the Priester and Petty (1996) measure of ambivalence and illusory perceptions of order $(r=.28, p=.013)$. The ambivalence measure based on the generated thoughts showed a marginally significant correlation with illusory perceptions of order $(r=.21, p=.058)$. In terms of the number of false positives, the order condition did not differ from the disorder condition, $F(1,78)=1.42, p=.24$. These results are summarized in Table 1 .

The results of this study replicate the earlier finding that ambivalence fosters illusory perceptions of order and extend these findings by showing that affirming perceptions of order reduces this need. In other words, when perceptions of order are enhanced, this curtails the effect of ambivalence on compensatory order strategies. This finding substantiates our notion that the effects obtained in the first two studies are caused by a need to regain compensatory order and that affirming order can indeed fulfill this need.

\section{General Discussion}

In a society where individuals are increasingly exposed to evaluatively incongruent information, attitudinal ambivalence is something with which people have to come to terms. Earlier research on this topic has predominantly addressed how information processing is guided by the motivation to reduce ambivalence and change the ambivalent attitude into a univalent one. The research presented in this paper shows that there are also compensatory strategies people employ in an attempt to cope with the unpleasant experience of ambivalence. We have shown that the evaluative inconsistency that is ambivalence leads to a motivation to perceive (compensatory) order elsewhere, and the current studies have shown that ambivalence indeed promotes such perceptions of order. In Study 1 we found that ambivalence leads to an increase in illusory pattern perception, suggesting ambivalent attitude holders are indeed looking for order and structure. In Study 2 we showed that ambivalence leads to an increased belief in conspiracy theories and that this effect is mediated by the negative

\footnotetext{
${ }^{4}$ The fact that the absolute number of false positives is higher than in Study 1 is likely due to the fact that the pictures were presented one by one on a computer screen, with the pictures being larger than in the paper-andpencil task of Study 1.
} 
Table 1

Number of False Positives on Modified Snowy Pictures Task by Condition, Study 3

\begin{tabular}{lcc}
\hline & Univalent & $\frac{\text { Ambivalent }}{M(S D)}$ \\
\cline { 2 - 3 } Condition & $4.40(2.80)_{\mathrm{a}}$ & $9.15(3.53)_{\mathrm{b}}$ \\
\hline Disorder & $6.15(4.32)_{\mathrm{a}}$ & $5.45(3.83)_{\mathrm{a}}$ \\
\hline
\end{tabular}

Note. Letters in subscript indicate which means differ significantly from one another $(p<.05)$.

emotions elicited by ambivalence, providing support for our assumption that it is the unpleasant affective nature of ambivalence that drives the motivation to perceive compensatory order. In Study 3 we found that ambivalence leads to an increase in illusory pattern perception but not after a preceding affirmation of order. This finding supports our notion that the effects in the first two studies are indeed driven by a desire to perceive order.

Although we suggest that it is the need for order that drives the effects in each of the studies, one could possibly bring forward alternative explanations for the findings obtained with each of the dependent measures. For example, with regard to the modified snowy pictures task, one could argue that ambivalent participants saw more false positives in the modified snowy pictures task because ambivalence may foster dialectical thinking (Hamamura, Heine, \& Paulhus, 2008), which in turn has been associated with creativity (Benack, Basseches, \& Swan, 1989). One could also argue that cleaning up the cubicle not only generated an orderly environment but was also self-affirming (Whitson \& Galinksy, 2008, Study 6). However, taking all three studies and the measure of conspiracy beliefs as a dependent measure in Study 2 into account, we believe that desire for order is the most parsimonious explanation for the observed findings.

In the present paper and in previous studies on coping with ambivalence (e.g., Nordgren et al., 2006; van Harreveld, van der Pligt, \& de Liver, 2009) we have argued that ambivalence leads to negative affect and that this negative affect, in turn, ignites subsequent coping processes. Although we believe this is the most likely pathway, we cannot rule out alternative models. For example, it could be the case that, especially in the context of an important dichotomous decision, the experience of ambivalence leads to a sense of loss of control over the situation as the ambivalent decision maker is (unwillingly) forced to make a dichotomous choice (van Harreveld, Rutjens, et al., 2009). This lack of control in turn could trigger the negative affective response. The interplay between various forms of psychological threat and subsequent coping processes is something future research could address.

The current findings are crucial for various reasons. First of all, ambivalence is considered an important concept in research on attitudes (Thompson et al., 1995), with a host of established consequences for affect (e.g., Hass et al., 1992; van Harreveld, Rutjens, et al., 2009) and the processing of information that is related to the attitude object (e.g., Clark et al., 2008; Maio et al., 1996; see van Harreveld, van der Pligt, \& de Liver, 2009, for an overview). The current research shows that the experience of ambivalence has consequences that go beyond the direct context of the attitude itself and extend to how the ambivalent attitude holder perceives the world, thereby rendering the arguably increasing prevalence of attitudinal ambivalence even more meaningful.

Second, the present findings help to put the concept of attitudinal ambivalence in a broader theoretical perspective. We have shown that the experience of attitudinal ambivalence shares characteristics with other psychological threats. In particular, the compensatory need for order that ambivalence generates is also observed for personal uncertainty (e.g., McGregor et al., 2010) and lack of control (Kay, Gaucher, Napier, Callan, \& Laurin, 2008). Although these concepts also generate a need for order, they are conceptually quite different from ambivalence. For example, perceptions of control can, but certainly do not always, play a role in the context of ambivalence. For someone who is dieting, feeling little control over the desire to eat large amounts of ice cream can contribute to his or her experienced ambivalence. However, in many cases personal control is less important; for example, in relation to societal issues such as the war in Afghanistan, euthanasia, or new abortion legislation as used in our Study 1.

As suggested earlier, (un)certainty has already been distinguished from ambivalence by various researchers (e.g., Bassili, 1996; Clarkson et al., 2008; Rucker \& Petty, 2004; Rucker et al., 2008). Shepherd, Kay, Landau, and Keefer (2011) recently showed that different psychological threats elicit different kinds of compensatory coping responses. Even more recently, however, Proulx et al. (2012) argued that inconsistency-related threats such as ambivalence, dissonance, mortality salience, and threats to personal control share important characteristics. In the introduction we reasoned that ambivalence has unique characteristics that distinguish it from other psychological threats, in terms both of its experience and of the coping responses it elicits (see Galinsky, Whitson, Huang, and Rucker, 2012, for a reply arguing for content-specific compensation). Future research should further pursue this matter and investigate how various psychological threats relate to one another and what a need for order appeals to in each of these cases.

Another matter that should be addressed in subsequent research is the exact compensatory nature of ambivalence-induced perceptions of order. The current studies indicate, first, that the negative affective nature of ambivalence causes the desire to perceive order and, second, that affirming order renders these compensatory order perceptions obsolete. However, it remains to be seen whether the negative affect that ambivalence can elicit (e.g., van Harreveld, Rutjens, et al., 2009) is diminished by compensatory perceptions, as observed in the present studies. In subsequent studies on this matter, specific attention should be given to the specific kind of affective response that is targeted by compensatory order perceptions. In the present studies, in accordance with earlier research, we operationalized ambivalence-induced discomfort with a set of uncertainty-related emotions. It would be useful to (a) elucidate the exact nature of the ambivalence-induced affective response and (b) determine whether, for example, compensatory order perceptions reduce the uncertainty and/or the anxiety that can be associated with ambivalence.

The current findings shed more light on how ambivalent attitudes can persist. It has long been argued that ambivalence can be experienced as unpleasant because it constitutes a violation of consistency motives. If an unpleasant perception of one's evaluative incongruency would always be alleviated by changing from an 
ambivalent to a univalent attitude, ambivalence would mostly be a transient state and people would generally become less ambivalent. However, though thinking yourself toward a univalent attitude is indeed a way to deal with the negative feelings ambivalence can elicit (e.g., Nordgren et al., 2006), the current research shows that there are other ways as well. Compensatory coping does not address the root of the problem (i.e., the attitude itself), but it may make it easier to tolerate feelings of ambivalence. The notion that we may accept our ambivalent feelings by engaging in compensatory coping suggests that our continuous exposure to evaluatively inconsistent information may lead to an increase in ambivalence and thus also to an increased need to view the world around us as an orderly place. This suggests that any belief that provides order, such as belief in progress (Rutjens, van Harreveld, \& van der Pligt, 2010), in science (Rutjens, van Harreveld, van der Pligt, Kreemers, \& Noordewier, 2013), in social organization (Friesen, Kay, Eibach, \& Galinsky, in press), or in a just world (Lerner \& Simmons, 1966), could be effective as well. The effectiveness of compensatory coping strategies in reducing ambivalence-induced discomfort is something that future research should address.

Ambivalent attitude holders can cope with their discomfort by addressing the root of the problem directly and attempting to tip the balance within the attitude to one evaluative side (van Harreveld, van der Pligt, \& de Liver, 2009), or they can employ strategies, such as investigated in the present studies, that are likely to leave the attitude intact. The question remains when each of these two coping categories is preferred. A first factor that likely predicts this preference is whether or not a dichotomous choice vis-à-vis the attitude object has to be made. Many people can remain ambivalent about a topic such as abortion without having to make a discrete choice. However, when the topic suddenly becomes personally relevant and one has to take an unequivocal stance, the mixed evaluations become irreconcilable and unpleasant (van Harreveld, Rutjens, et al., 2009). Trying to change one's overall attitude is in that case likely a more effective approach than perceiving order elsewhere.

Contextual factors apart from situations that force choice may play a role in predicting the strategies employed by those who experience ambivalence as unpleasant. Van Harreveld, van der Pligt, and de Liver (2009) argued that ambivalent attitude holders are flexible in dealing with their discomfort in the sense that when each of the coping strategies is most likely to be employed depends on the specific possibilities and constraints in a given situation. They suggested more specifically that, when the aim is to directly reduce ambivalence, the availability of cognitive resources plays an important role in determining whether effortful or less effortful information processing strategies are employed. Future research could shed light on whether direct systematic information processing strategies that aim at changing the ambivalent attitude require more cognitive resources than do the compensatory beliefs investigated in the current research. If this is indeed the case, the combination of both resources (e.g., glucose levels; cf. Gailliot \& Baumeister, 2007) and motivation (e.g., an imminent dichotomous choice, cf. van Harreveld, Rutjens, et al., 2009) to invest cognitive effort into reducing ambivalence-induced discomfort is likely to predict whether direct or compensatory strategies are employed.

The current research has shown that the unpleasant nature of ambivalence increases belief in conspiracy theories. Although for centuries world leaders, from Caesar to Lincoln, have fallen victim to actual conspiracies, the public belief that (mostly negative) events can be attributed to conspiracies has gained momentum over the last couple of decades (e.g., Lewandowsky, Oberauer, \& Gignac, 2013; Wood, Douglas, \& Sutton, 2012). Most Americans nowadays believe that the murder of John F. Kennedy was part of a conspiracy. Conspiracies have also been suggested in the context of a myriad of "events," such as the 9/11 attacks, President Obama's birth certificate, global warming, the deaths of Princess Diana and Osama bin Laden, the moon landing, and even the 2004 Indian Ocean tsunami. In fact, Fenster (2008) argued, "We are all conspiracy theorists now," and the increase in attitudinal ambivalence in modern society may thus be one explanation for the increase in adherence to conspiracy theories.

In sum, although ambivalence has likely always been a part of human existence, in an age where individuals are confronted with increasing amounts of information from an increasing number of sources, ambivalence is more an intrinsic part of people's lives than it has ever been. The current research suggests that this increase in ambivalence has important ramifications for the way in which the world is perceived.

\section{References}

Alvarez, R. M., \& Brehm, J. (1995). American ambivalence towards abortion policy: Development of a heteroskedastic probit model of competing values. American Journal of Political Science, 39, 10551082. doi: $10.2307 / 2111669$

Armitage, C. J., \& Arden, M. A. (2007). Felt and potential ambivalence across the stages of change. Journal of Health Psychology, 12, 149-158. doi:10.1177/1359105307071749

Bassili, J. N. (1996). Meta-judgmental versus operative indexes of psychological attributes: The case of measures of attitude strength. Journal of Personality and Social Psychology, 71, 637-653. doi:10.1037/00223514.71.4.637

Benack, S., Basseches, M., \& Swan, T. (1989). Dialectical thinking and adult creativity. In J. A. Glover, R. R. Ronning, \& C. R. Reynolds (Eds.), Handbook of creativity. Perspectives on individual differences ( $\mathrm{pp}$ 199-208). New York, NY: Plenum Press.

Brehm, J. W. (2007). A brief history of dissonance theory. Social and Personality and Psychology Compass, 1, 381-391. doi:10.1111/j.17519004.2007.00035.x

Brückner, H., Martin, A., \& Bearman, P. S. (2004). Ambivalence and pregnancy: Adolescents' attitudes, contraceptive use and pregnancy. Perspectives on Sexual and Reproductive Health, 36, 248-257. doi: $10.1363 / 3624804$

Clark, J. K., Wegener, D. T., \& Fabrigar, L. R. (2008). Attitudinal ambivalence and message-based persuasion: Motivated processing of proattitudinal information and avoidance of counterattitudinal information. Personality and Social Psychology Bulletin, 34, 565-577. doi:10.1177/ 0146167207312527

Clarkson, J. J., Tormala, Z. L., \& Rucker, D. D. (2008). A new look at the consequences of attitude certainty: The amplification hypothesis. Journal of Personality and Social Psychology, 95, 810-825. doi:10.1037/ a0013192

Coser, R. L. (1976). Authority and structural ambivalence in the middleclass family. In L. A. Coser \& B. Rosenberg (Eds.), Sociological theory (pp. 566-576). New York, NY: Macmillan.

Cunningham, W. A., Johnson, M. K., Gatenby, J. C. G., Gore, J. C., \& Banaji, M. R. (2003). Neural components of social evaluation. Journal of Personality and Social Psychology, 85, 639-649. doi:10.1037/00223514.85.4.639 
Ekstrom, R. B., French, J. W., Harman, H. H., \& Dermen, D. (1976). Manual for kit of factor-referenced cognitive tests. Princeton, NJ: Educational Testing Service.

Fenster, M. (2008). Conspiracy theories: Secrecy and power in American culture. Minneapolis: University of Minnesota Press.

Freud, S. (1957). The unconscious. In J. Strachey (Ed. \& Trans.), The standard edition of the complete psychological works of Sigmund Freud (Vol. 14, pp. 166-215). London, England: Hogarth. (Original work published 1915)

Freud, S. (1964). Civilization and its discontents. London, England: Hogarth. (Original work published 1930)

Friesen, J. P., Kay, A. C., Eibach, R. P., \& Galinsky, A. D. (in press). Seeking structure in social organization: Compensatory control and the psychological advantages of hierarchy. Journal of Personality and Social Psychology. doi:10.1037/a0035620

Gailliot, M. T., \& Baumeister, R. F. (2007). The psychology of willpower: Linking blood glucose to self-control. Personality and Social Psychology Review, 11, 303-327. doi:10.1177/1088868307303030

Galinsky, A. D., Whitson, J. A., Huang, L., \& Rucker, D. D. (2012). Not so fluid and not so meaningful: Toward an appreciation of contentspecific compensation. Psychological Inquiry, 23, 339-345. doi: 10.1080/1047840X.2012.730978

Glick, P., \& Fiske, S. T. (1999). The Ambivalence Toward Men Inventory: Differentiating hostile and benevolent beliefs about men. Psychology of Women Quarterly, 23, 519-536. doi:10.1111/j.1471-6402.1999 tb00379.x

Greenberg, J., Solomon, S., \& Pyszczynski, T. (1997). Terror management theory of self-esteem and cultural worldviews: Empirical assessments and conceptual refinements. Advances in Experimental Social Psychology, 29, 61-139. doi:10.1016/S0065-2601(08)60016-7

Hamamura, T., Heine, S. J., \& Paulhus, D. L. (2008). Cultural differences in response styles: The role of dialectical thinking. Personality and Individual Differences, 44, 932-942. doi:10.1016/j.paid.2007.10.034

Has, R. G., Katz, I., Rizzo, N., Bailey, J., \& Moore, L. (1992). When racial ambivalence evokes negative affect, using a disguised measure of mood. Personality and Social Psychology Bulletin, 18, 786-797. doi:10.1177/ 0146167292186015

Heider, F. (1946). Attitudes and cognitive organization. Journal of Psychology, 21, 107-112. doi:10.1080/00223980.1946.9917275

Higgins, E. T. (1987). Self-discrepancy: A theory relating self and affect. Psychological Review, 94, 319-340. doi:10.1037/0033-295X.94.3.319

Jamieson, D. W. (1993, August). The attitude ambivalence construct: Validity, utility, and measurement. Paper presented at the meeting of the American Psychological Association, Toronto, Ontario, Canada.

Jonas, K., Diehl, M., \& Brömer, P. (1997). Effects of attitudinal ambivalence on information processing and attitude-intention consistency. Journal of Experimental Social Psychology, 33, 190-210. doi:10.1006/ jesp.1996.1317

Kaplan, K. J. (1972). On the ambivalence-indifference problem in attitude theory and measurement: A suggested modification of the semantic differential technique. Psychological Bulletin, 77, 361-372. doi: $10.1037 / \mathrm{h} 0032590$

Katz, I. (1981). Stigma: A social psychological analysis. Hillsdale, NJ: Erlbaum.

Katz, I., \& Hass, R. G. (1988). Racial ambivalence and American value conflict: Correlational and priming studies of dual cognitive structures. Journal of Personality and Social Psychology, 55, 893-905. doi: 10.1037/0022-3514.55.6.893

Kay, A. C., Gaucher, D., McGregor, I., \& Nash, K. (2010). Religious belief as compensatory control. Personality and Social Psychology Review, 14, 37-48. doi:10.1177/1088868309353750

Kay, A. C., Gaucher, D., Napier, J. L., Callan, M. J., \& Laurin, K. (2008). God and the government: Testing a compensatory control mechanism for the support of external systems. Journal of Personality and Social Psychology, 95, 18-35. doi:10.1037/0022-3514.95.1.18

Kay, A. C., Whitson, J. A., Gaucher, D., \& Galinksy, A. D. (2009). Compensatory control. Achieving order through the mind, our institutions, and the heavens. Current Directions in Psychological Science, 18, 264-268. doi:10.1111/j.1467-8721.2009.01649.x

Lavine, H. (2001). The electoral consequences of ambivalence toward presidential candidates. American Journal of Political Science, 45, 915929. doi: $10.2307 / 2669332$

Lerner, M. J., \& Simmons, C. H. (1966). Observer reaction to the "innocent victim": Compassion or rejection? Journal of Personality and Social Psychology, 4, 203-210. doi:10.1037/h0023562

Lewandowsky, S., Oberauer, K., \& Gignac, G. E. (2013). NASA faked the moon landing-Therefore (climate) science is a hoax: An anatomy of the motivated rejection of science. Psychological Science, 24, 622-633. doi:10.1177/0956797612457686

Luescher, K., \& Pillemer, K. (1998). Intergenerational ambivalence: A new approach to the study of parent-child relations later in life. Journal of Marriage and the Family, 60, 413-425. doi:10.2307/353858

Maio, G. R., Bell, D. W., \& Esses, V. M. (1996). Ambivalence and persuasion: The processing of messages about immigrant groups. Journal of Experimental Social Psychology, 32, 513-536. doi:10.1006/jesp .1996 .0023

McGregor, I., Nash, K., Mann, N., \& Phills, C. E. (2010). Anxious uncertainty and reactive approach motivation (RAM). Journal of Personality and Social Psychology, 99, 133-147. doi:10.1037/a0019701

McGregor, I., Newby-Clark, I. R., \& Zanna, M. P. (1999). "Remembering" dissonance: Simultaneous accessibility of inconsistent cognitive elements moderates epistemic discomfort. In E. Harmon-Jones \& J. Mills (Eds.), Cognitive dissonance: Progress on a pivotal theory in social psychology (pp. 325-353). doi:10.1037/10318-013

McGregor, I., Zanna, M. P., Holmes, J. G., \& Spencer, S. J. (2001). Compensatory conviction in the face of personal uncertainty: Going to extremes and being oneself. Journal of Personality and Social Psychology, 80, 472-488. doi:10.1037/0022-3514.80.3.472

Mitroff, I. (1974). Norms and counternorms in a select group of the Apollo moon scientists: A case study of the ambivalence of scientists. American Sociological Review, 39, 579-595. doi:10.2307/2094423

Monteith, M. J., Devine, P. G., \& Zuwerink, J. R. (1993). Self-directed versus other-directed affect as a consequence of prejudice-related discrepancies. Journal of Personality and Social Psychology, 64, 198-210. doi:10.1037/0022-3514.64.2.198

Müller, U., Carpendale, J. I. M., \& Smith, L. (Eds.). (2009). The Cambridge companion to Piaget. New York, NY: Cambridge University Press.

Newby-Clark, I. R., McGregor, I., \& Zanna, M. P. (2002). Thinking and caring about cognitive inconsistency: When and for whom does attitudinal ambivalence feel uncomfortable? Journal of Personality and Social Psychology, 82, 157-166. doi:10.1037/0022-3514.82.2.157

Nohlen, H. U., van Harreveld, F., Rotteveel, M., Lelieveld, G. J., \& Crone, E. (2013). Evaluating ambivalence: Social-cognitive and affective brain regions associated with ambivalent decision-making. Social Cognitive and Affective Neuroscience. Advance online publication. doi:10.1093/ scan/nst074

Nordgren, L. F., van Harreveld, F., \& van der Pligt, J. (2006). Ambivalence, discomfort, and motivated information processing. Journal of Experimental Social Psychology, 42, 252-258. doi:10.1016/j.jesp.2005 .04 .004

Ostrom, T. M. (1969). The relationship between the affective, behavioral and cognitive components of attitude. Journal of Experimental Social Psychology, 5, 12-30. doi:10.1016/0022-1031(69)90003-1

Pipes, D. (1997). Conspiracy: How the paranoid style flourishes and where it comes from. New York, NY: Free Press. 
Povey, R., Wellens, B., \& Conner, M. (2001). Attitudes towards following meat, vegetarian and vegan diets: An examination of the role of ambivalence. Appetite, 37, 15-26. doi:10.1006/appe.2001.0406

Priester, J. R., \& Petty, R. E. (1996). The gradual threshold model of ambivalence: Relating the positive and negative bases of attitudes to subjective ambivalence. Journal of Personality and Social Psychology, 71, 431-449. doi:10.1037/0022-3514.71.3.431

Priester, J. R., \& Petty, R. E. (2001). Extending the bases of subjective attitudinal ambivalence: Interpersonal and intrapersonal antecedents of evaluative tension. Journal of Personality and Social Psychology, 80, 19-34. doi:10.1037/0022-3514.80.1.19

Proulx, T., \& Heine, S. J. (2008). The case of the transmogrifying experimenter: Reaffirmation of moral schema following implicit change detection. Psychological Science, 19, 1294-1300. doi:10.1111/j.14679280.2008.02238.x

Proulx, T., \& Inzlicht, M. (2012). Moderated disanxiousuncertlibrium: Specifying the moderating and neuroaffective determinants of violationcompensation effects. Psychological Inquiry, 23, 386-396. doi:10.1080/ 1047840X.2012.734912

Proulx, T., Inzlicht, M., \& Harmon-Jones, E. (2012). Understanding all inconsistency compensation as a palliative response to violated expectations. Trends in Cognitive Sciences, 16, 285-291. doi:10.1016/j.tics .2012 .04 .002

Rosenblum, A., Magura, S., \& Joseph, H. (1991). Ambivalence toward methadone treatment among intravenous drug users. Journal of Psychoactive Drugs, 23, 21-27. doi:10.1080/02791072.1991.10472571

Rucker, D. D., \& Petty, R. E. (2004). When resistance is futile: Consequences of failed counterarguing for attitude certainty. Journal of Personality and Social Psychology, 86, 219-235. doi:10.1037/0022-3514 86.2.219

Rucker, D. D., Petty, R. E., \& Brinol, P. (2008). What's in a frame anyway? A meta-cognitive analysis of the impact of one versus two sided message framing on attitude certainty. Journal of Consumer Psychology, 18, 137-149. doi:10.1016/j.jcps.2008.01.008

Rutjens, B. T., van der Pligt, J., \& van Harreveld, F. (2009). Things will get better: The anxiety-buffering qualities of progressive hope. Personality and Social Psychology Bulletin, 35, 535-543. doi:10.1177/ 0146167208331252

Rutjens, B. T., van Harreveld, F., \& van der Pligt, J. (2010). Yes we can: Belief in progress as compensatory control. Social Psychological \& Personality Science, 1, 246-252. doi:10.1177/1948550610361782

Rutjens, B. T., van Harreveld, F., van der Pligt, J., Kreemers, L. M., \& Noordewier, M. K. (2013). Steps, stages, and structure: Finding compensatory order in scientific theories. Journal of Experimental Psychology: General, 142, 313-318. doi:10.1037/a0028716

Schneider, I. K., Eerland, A., van Harreveld, F., Rotteveel, M., van der Pligt, J., van der Stoep, N., \& Zwaan, R. (2013). One way and the other: The bidirectional relationship between ambivalence and body movement. Psychological Science, 24, 319-325. doi:10.1177/ 0956797612457393

Shepherd, S., Kay, A. C., Landau, M. J., \& Keefer, L. A. (2011). Evidence for the specificity of control motivations in worldview defense: Distin- guishing compensatory control from uncertainty management and terror management processes. Journal of Experimental Social Psychology, 47, 949-958. doi:10.1016/j.jesp.2011.03.026

Signorielli, N. (1991). Adolescents and ambivalence toward marriage: A cultivation analysis. Youth and Society, 23, 121-149. doi:10.1177/ 0044118X91023001006

Slater, P., \& Slater. D. (1965). Maternal ambivalence and narcissism: A cross-cultural study. Merrill-Palmer Quarterly, 11, 241-259.

Steele, C. M., \& Liu, T. J. (1983). Dissonance processes as selfaffirmation. Journal of Personality and Social Psychology, 45, 5-19. doi:10.1037/0022-3514.45.1.5

Thompson, M. M., Zanna, M. P., \& Griffin, D. W. (1995). Let's not be indifferent about (attitudinal) ambivalence. In R. E. Petty \& J. A. Krosnick (Eds.), Attitude strength: Antecedents and consequences (pp. 361-386). Mahwah, NJ: Erlbaum.

van den Bos, K. (2001). Uncertainty management: The influence of uncertainty salience on reactions to perceived procedural fairness. Journal of Personality and Social Psychology, 80, 931-941. doi:10.1037/00223514.80.6.931

van Harreveld, F., Rutjens, B. T., Rotteveel, M., Nordgren, L. F., \& van der Pligt, J. (2009). Ambivalence and decisional conflict as a cause of psychological discomfort: Feeling tense when jumping off the fence. Journal of Experimental Social Psychology, 45, 167-173. doi:10.1016/ j.jesp.2008.08.015

van Harreveld, F., \& van der Pligt, J. (2004). Attitudes as stable and transparent constructions. Journal of Experimental Social Psychology, 40, 666-674. doi:10.1016/j.jesp.2003.12.004

van Harreveld, F., van der Pligt, J., \& de Liver, Y. (2009). The agony of ambivalence and ways to resolve it: Introducing the MAID model Personality and Social Psychology Review, 13, 45-61. doi:10.1177| 1088868308324518

van Harreveld, F., van der Pligt, J., de Vries, N. K., Wenneker, C., \& Verhue, D. (2004). Ambivalence and information integration in attitudinal judgment. British Journal of Social Psychology, 43, 431-447. doi:10.1348/0144666042037971

Wexler, P. (1983). Critical social psychology. London, England: Routledge \& Kegan Paul.

Whitson, J. A., \& Galinksy, A. D. (2008, October 3). Lacking control increases illusory pattern perception. Science, 322, 115-117. doi: $10.1126 /$ science. 1159845

Wiseman, J. P. (1976). The social psychology of sex. New York, NY: Harper \& Row.

Wood, M. J., Douglas, K. M., \& Sutton, R. M. (2012). Dead and alive: Beliefs in contradictory conspiracy theories. Social Psychological \& Personality Science, 3, 767-773. doi:10.1177/1948550611434786

Yinger, J. M. (1982). Countercultures. New York, NY: Free Press.

Received November 30, 2012

Revision received January 17, 2014

Accepted January 24, 2014 